\section{The rapid interphase chromosome assay (RICA) implementation: comparison with other PCC methods}

\begin{abstract}
A report is presented on the advantages of the rapid interphase chromosome assay (RICA) and the difficulties that may be met while implementing this method for application in biological dosimetry. The RICA test can be applied on unstimulated human lymphocytes; this is an advantage in comparison with the dicentric chromosomes or micronucleus tests. In the former two tests, stimulated lymphocytes are examined and hence, $48 \mathrm{~h}$ more are needed to obtain cells traversing the cell cycle. Due to the use of unstimulated nondividing cells, higher numbers of cells are available for RICA analysis than for dicentric chromosomes or micronuclei tests. Moreover, the method can be applied after exposure to ionizing radiation doses in excess of 5 Gy. Such doses cause a significant cell cycle delay or result in the loss of G2 phase and mitotic cells because of apoptosis. Therefore, the traditional biodosimetry based on the evaluation of the incidence of damage to chromosomes is very difficult to carry out. This is due to the lack of an adequate number of mitotic cells for analysis. RICA is free of this disadvantage. An automatic microscope can be used to retrieve cell images; automatic image analysis can also be used.
\end{abstract}

Key words: biodosimetry $\bullet$ ionizing radiation $\bullet$ premature chromosome condensation (PCC) • human lymphocytes

S. Sommer ${ }^{\bowtie}$, I. Buraczewska, K. Sikorska,

T. Bartłomiejczyk, I. Szumiel

Centre for Radiobiology and Biological Dosimetry, Institute of Nuclear Chemistry and Technology, 16 Dorodna Str., 03-195 Warsaw, Poland, Tel.: +48 22504 1228, Fax: +48 22504 1341, E-mail: s.sommer@ichtj.waw.pl

\section{Kruszewski}

Centre for Radiobiology and Biological Dosimetry, Institute of Nuclear Chemistry and Technology,

16 Dorodna Str., 03-195 Warsaw, Poland and Department of Medical Biology and Translational Research,

Faculty of Medicine,

University of Information Technology and

Management,

2 Sucharskiego Str., 35-225 Rzeszów, Poland

Received: 16 January 2015

Accepted: 10 August 2015

\section{Introduction}

Biological dosimetry methods that enable the estimation of the absorbed dose of ionizing radiation are based on an examination of morphological changes in the chromosomes of peripheral blood lymphocytes (PBL). The gold standard of biological dosimetry is the dicentric chromosomes test (a result of radiation-induced translocation), considered trustworthy, even when scoring is carried out in QuickScan mode [1-3]. QuickScan mode is a much faster way of scoring dicentrics, whereby aberrations are first spotted and then the completeness of the mitotic cell - the presence of 46 chromosomes - is confirmed. In addition, the analysis of micronuclei frequency (the cytokinesis-block micronucleus assay) $[4,5]$ or the analysis of the number of phosphorylated histone $\mathrm{H} 2 \mathrm{AX}(\gamma-\mathrm{H} 2 \mathrm{AX})$ foci [6-8] can be used as less laborious surrogate methods. When the dicentric chromosomes or micronuclei are to be counted, the cells must pass mitosis. This, in some 
cases, may be difficult to achieve. After high doses of radiation, the heavily damaged cells can remain in the G2/M block for a long time, so that they will not be included in the pool of cells analyzed. This may lead to an underestimation of the radiation dose or in extreme cases, makes the analysis impossible.

The method of premature chromosome condensation (PCC) is used in biological dosimetry for the estimation of high doses of radiation, where the classic dosimetric tests cannot be used. PCC can be applied for interphase cells. In the case of chemically induced PCC, both the entry of $\mathrm{G}_{0} \mathrm{lym}$ phocytes into the cell cycle and reaching the G2/M phase are necessary. In the alternative approach, the merging with the mitotic Chinese hamster ovary (CHO) cells, the entry of lymphocytes into the cell cycle is not necessary.

Further methodological progress was made by Prasanna et al. $[9,10]$, who described a new variant of the PCC method, the rapid interphase chromosome assay (RICA). At first glance, RICA appears relatively simple and fast in execution. It involves the partial condensation of the chromatin of the unstimulated human lymphocytes. This effect is obtained by the treatment with inhibitors of serine/ threonine protein phosphatases (PP1 and PP2A), calyculin A or okadaic acid, in the presence of ATP and the cyclin-dependent kinase 1 (CDK1)-cyclin B kinase complex, an essential component of the mitosis-promoting complex. Within a few hours from the start of the treatment, lymphocytes with partially condensed chromatin are obtained. To count the ionizing radiation-induced aberrations in a chosen chromosome, chromosome painting is applied using a whole-chromosome probe and the fluorescence in situ hybridization (FISH) method. Cells with the aberrant chromosome are seen to have more than two chromosome spots. The FISH method takes 24 hours. Thus, microscopic preparations suitable for analysis are ready at least one day earlier than those in the classic tests of biological dosimetry. The dose limit that is essential in the classic tests, as mentioned above, does not apply.

Upon analysis of the respective bibliography [11-19], we decided to implement the RICA method for the current biodosimetry work carried out at the Biological Dosimetry Laboratory of the Centre for Radiobiology and Biological Dosimetry, Institute of Nuclear Chemistry and Technology. Here, we evaluate the RICA method, report on its adaptation to the analytical tools available in the lab and compare it with two other PCC methods. We hope that the detailed description will allow other biodosimetry labs to avoid the errors that might be connected with implementation of RICA.

\section{Materials and methods}

\section{Human peripheral blood lymphocytes}

After obtaining informed consent, peripheral blood from healthy adult donors was collected into vacutainers with sodium heparin (S-Monovette,
Sarstedt). Depending on the method used, the blood samples were treated in different ways.

\section{The rapid interphase chromosome assay}

The RICA method was performed according to Prasanna [9] with minor changes.

\section{Blood separation}

After venipuncture, lymphocytes were separated from whole blood according to the standard protocol used at the Institute of Nuclear Chemistry and Technology. Briefly, centrifuge tubes were filled with cold Histopaque and blood diluted twice in RPMI 1640 was gently dropped on the Histopaque surface (1 part Histopaque, 1 part of blood) and centrifuged (1000 RPM for half an hour). Then, the middle layer with white blood cells was transferred to another tube and washed three times with PBS and re-suspended in a complete RPMI 1640 medium. Before washing steps, the lymphocytes were counted using a Thoma cell counting chamber. Finally, $2 \mathrm{ml}$ cultures were set with 1 million cells per milliliter.

\section{Lymphocyte irradiation}

The isolated lymphocytes were sham irradiated or irradiated with different doses of X-rays (Xylon defectoscope, $200 \mathrm{kV}, 4.5 \mathrm{~mA}, 0.8 \mathrm{~mm}$ Al filter) in culture tubes, in a water bath, at $37^{\circ} \mathrm{C}$. Then, the lymphocytes were left in the incubator for $2 \mathrm{~h}$.

\section{Phosphate inhibitors and cell fixation}

Next, the lymphocyte cultures were subjected to treatment with calyculin A $(50 \mathrm{nM})$ for $45 \mathrm{~min}$ or with okadaic acid $(0.75 \mathrm{mM}$, Sigma) for $3 \mathrm{~h}$ in the presence of ATP $(200 \mu \mathrm{M}$, Sigma $)$ and the CDK1-cyclin B complex (at a concentration of 0,5 , or 20 units per lymphocyte culture, New England Biolabs, Beverly, MA, USA). Then, the cells were centrifuged, treated with hypotonic solution $(0.075 \mathrm{M} \mathrm{KCl})$, fixed 3 times with Carnoy's fixative (acetic acid/methanol, $1: 3)$ and spotted on the wet microscopic slides.

\section{Chromosome territory painting}

The chromosome territories were painted with a whole chromosome one probe (Metasystems) according to the protocol of the manufacturers. $10 \mu \mathrm{l}$ of the probe mixture was applied to each slide, covered with a coverslip $22 \times 22 \mathrm{~mm}^{2}$ and sealed with rubber cement. Then, the samples and probe were denatured simultaneously by heating the slide on a hotplate at $75^{\circ} \mathrm{C}$ for $2 \mathrm{~min}$ and left in a humidified chamber at $37^{\circ} \mathrm{C}$ overnight. Next day, the coverslips were removed and the slides were washed in $0.4 \times$ SSC (pH 7.0) at $72^{\circ} \mathrm{C}$ for $2 \mathrm{~min}$, then drained and washed in $2 \times$ SSC, $0.05 \%$ Tween-20 (pH 7.0) at room temperature for $30 \mathrm{~s}$, rinsed briefly in distilled water and air dried. The cells were stained with DAPI/antifade solution (Vectashield). 


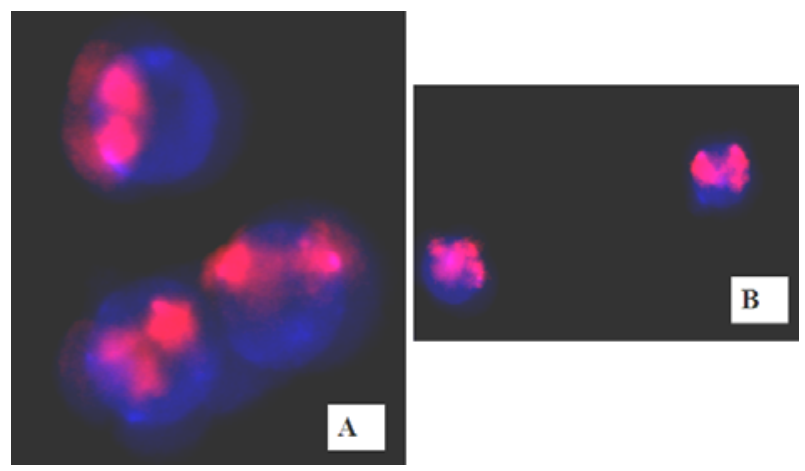

Fig. 1. Nuclei of lymphocytes that were X-irradiated $(5 \mathrm{~Gy})$ and microscopic preparations made according to the rapid interphase chromosome assay procedure and Cytospin. Red stained are chromosome 1 (panel A) and chromosome 3 (panel B) territories. Additional territories can be seen induced by X-irradiation.

\section{Chromosome territory scoring}

The chromosome territories were scored with a Zeiss Imager Z2 fluorescent microscope and image analysis system, Metasystems (Germany). The slides were scanned by the Metafer module and images at magnification of $400 \times$ were recorded in DAPI and TexasRed channels. The images were merged and analysis was performed with the Isis module of Metasystems software, where background and upper and lower signal threshold corrections were available. Only separated nuclei with two or more signals (clearly distinct) were analyzed (Fig. 1).

\section{Fitting of the calibration curves}

All calibration curves presented in this paper were fitted to the linear model with the help of DoseEstimate software version 4.0, created by Liz Ainsbury from Health Protection Agency, England.

\section{Chemically induced premature chromosome condensation}

The chemically induced PCC method was used following Coco-Martin (1997) and Durante (1998) [11, 20].

\section{Blood venipuncture, irradiation and lymphocyte culture}

Blood was collected into $9 \mathrm{ml}$ heparinized vacutainers (Monovette) in the medical unit of the Institute, divided into $1 \mathrm{ml}$ samples in sterile Eppendorf tubes and irradiated (or sham irradiated) with different doses (dose range 0-20 Gy) of X-rays (Xylon defectoscope, $20 \mathrm{kV}, 4.5 \mathrm{~mA}, 0.8 \mathrm{~mm}$ Al filter, in water bath, at $37^{\circ} \mathrm{C}$ ). Then, the whole blood cultures were set up: $0.5 \mathrm{ml}$ of blood was added to $4.5 \mathrm{ml}$ RPMI with $20 \%$ of FBS, phytohaemagglutinin and antibiotics in a cell culture tube. Lymphocytes were cultivated in the incubator at $37^{\circ} \mathrm{C}$ and $5 \%$ $\mathrm{CO}_{2}$ atmosphere.

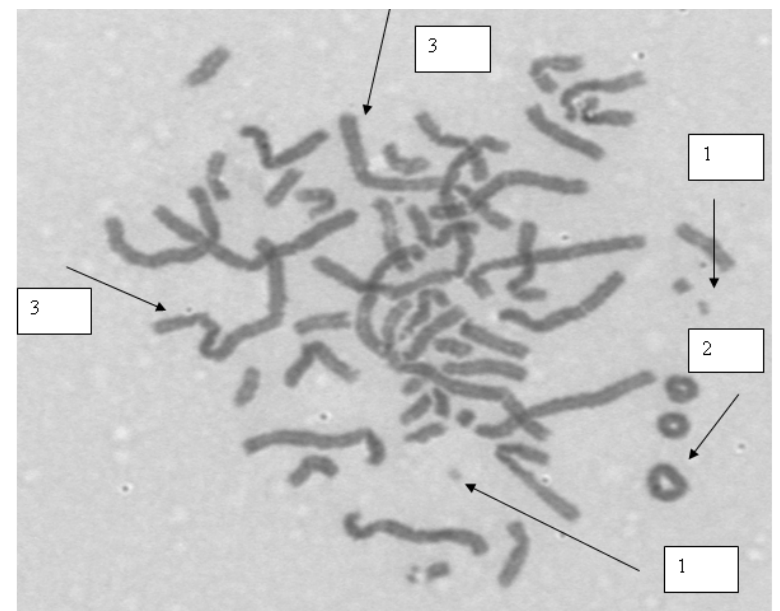

Fig. 2. Human lymphocyte chromosomes, $\gamma$-irradiated (5 Gy); PCC-induced chemically (okadaic acid). 1 - additional PCC fragments; 2 - three rings; 3 - long chromosomes resulting from fusion of several chromosomes.

\section{Chemical induction of PCC and cell fixation}

After $45 \mathrm{~h}$, calyculin A, an inhibitor of phosphatases PP1 and PP2A, was added to each cell culture to the final concentration of $50 \mathrm{nM}$, to induce PCC [21]. After $1 \mathrm{~h}$ the incubation cells were hypotonized ( $\mathrm{KCl}$ $0.075 \mathrm{M}$ ) and fixed with Carnoy's fixative. The cells were dropped on the microscopic slides and stained with Giemsa (3\%).

\section{Scoring of PCC fragments, rings, and long chromosomes}

PCC fragments, rings, and long chromosome were scored with a Zeiss Imager Z2 microscope and image analysis system Metasystems (Germany). The slides were scanned and recorded by the Metafer module and then analyzed using the microscope at a magnification of $630 \times$ (Fig. 2). We considered the round shape entities, often darkly stained, with or without the lumen, to be ring chromosomes. We considered the entities at least 1.5 times longer than the longest chromosome, that is, chromosome no. 1 , to be long chromosomes.

\section{Fusion-induced premature chromosome condensation}

The fusion-induced PCC method used in our laboratory follows with minor changes the protocols kindly provided by Dr Gabriel Pantelias and Dr Georgia Terzoudi from the Laboratory of Health Physics, Radiobiology \& Cytogenetics, Institute of Nuclear \& Radiological Sciences \& Technology, Energy \& Safety National Centre for Scientific Research "Demokritos" Greece, as well as Dr Firouz Darroudi from the College of North Atlantic-Qatar (previously, Senior Researcher at the Department of Toxicogenetics of the Leiden University Medical Centre (LUMC) in the Netherlands). Protocols are based on the publications of Pantelias and Maillie [22, 23]. 


\section{Lymphocyte separation}

Lymphocytes were separated as described above, washed three times and finally, kept in RPMI without serum. Lymphocytes isolated from $10 \mathrm{ml}$ of blood were used for at most 10 experimental points.

\section{Preparation of $\mathrm{CHO}$ mitotic cells}

CHO cells were cultured in DMEM/F12 medium with $10 \%$ of FBS in $25 \mathrm{~cm}^{2}$ culture flasks. Twenty hours before the experiment cells from one almost completely confluent culture flask were reseeded into three $25 \mathrm{~cm}^{2}$ culture flasks. Four hours before the start of cell fusion, colcemid $(0.2 \mu \mathrm{g} / \mathrm{ml})$ was added. The metaphase cells were harvested using the shake-off procedure. The mitotic cells from one $25 \mathrm{~cm}^{2}$ flask were used for two fusion procedures (two different experimental points). CHO mitotic cells were maintained in the presence of colcemid until used for fusion with the interphase lymphocytes and PCC induction.

\section{Irradiation of lymphocytes}

The isolated lymphocytes were sham irradiated or irradiated with different doses of $\mathrm{Co}^{60} \gamma$ rays in the range of 0-6 Gy (Minneyola $1000{ }^{60} \mathrm{Co}$ source, manufactured by the Institute of Nuclear Chemistry and Technology, Warsaw, Poland) in cell culture tubes, in a water bath at $37^{\circ} \mathrm{C}$. Immediately after irradiation, the fusion with $\mathrm{CHO}$ cells was initiated.

\section{Fusion of CHO mitotic cells with the isolated peripheral blood lymphocytes}

CHO mitotic cells were mixed with lymphocytes in round bottom culture tubes (in the presence of colcemid) and centrifuged together. Supernatants were poured off and the tubes were kept inverted while blotted with a paper towel and placed on a rack. One hundred and fifty micrograms of polyethylene glycol (PEG) solution (1 g PEG (MW 1450, Sigma-Aldrich) in $1.5 \mathrm{ml} \mathrm{RPMI} \mathrm{w/o} \mathrm{serum)} \mathrm{was} \mathrm{injected}$ directly into the cell pellet with an automatic pipette, the tubes were turned to the upright position and the contents gently mixed. After 1 minute $1.5 \mathrm{ml}$ of RPMI without serum containing colcemid was added slowly to the tubes and mixed with the PEG solution by gentle shaking. After centrifugation $(6 \mathrm{~min}$ at $1000 \mathrm{RPM})$, the supernatant was poured off and $0.7 \mathrm{ml}$ of pre-warmed RPMI containing colcemid (10 $\mu \mathrm{l}$ from stock solution) was added and the pellets were gently broken by tapping the tubes. Next, the tubes were incubated at $37^{\circ} \mathrm{C}$ for $70 \mathrm{~min}$. Subsequently, chromosome preparations were obtained using the standard procedure described above.

\section{Scoring of PCC fragments}

PCC fragments were scored with the help of a Zeiss Imager Z2 microscope and image analysis system Metasystems (Germany). The slides were scanned and recorded by the Metafer module and then ana-

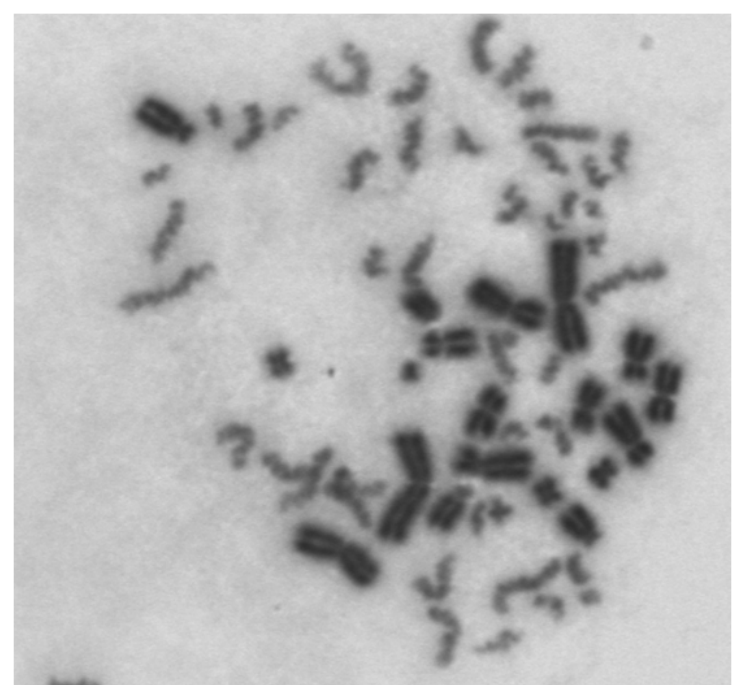

Fig. 3. Fusion of a mitotic Chinese hamster ovary cell (large, dark stained chromosomes with visible double chromatids) with an interphase human lymphocyte (smaller, less brightly stained chromosomes).

lyzed using microscope and magnification of $630 \times$. A number of smaller, less brightly stained lymphocyte chromosomes were scored in good quality fused cells as visible in Fig. 3.

\section{Results and discussion}

\section{Optimization of the FISH method}

In order to distinguish chromosome territories in the interphase nuclei, the FISH method was used. To test the efficiency of 'chromosome painting', chromosomes 1, 2, and 3 were painted with hybridization probes supplied by Metasystems. The painting of chromosome 1 gave the most intense pictures; therefore, this probe was chosen for further experiments. Hybridization was carried out on the stimulated PBL preparations, where numerous mitotic cells were present (Fig. 4). For these prepara-

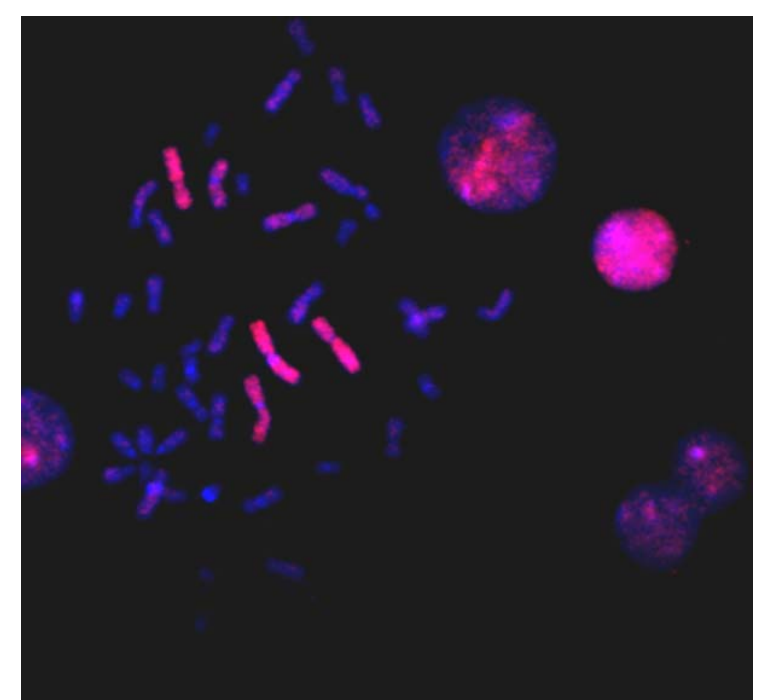

Fig. 4. Fluorescence in situ hybridization-painted human metaphase chromosomes 1,2 , and 3 . 
tions the painting of the condensed chromosomes was satisfactory. Therefore, we used this method as a positive control for the chromosome painting of the unstimulated PBL.

\section{Choice of the phosphatase inhibitor}

Since the RICA method is intended for unstimulated lymphocytes, the appropriate phosphatase inhibitor is necessary for the stimulation of chromatin condensation. We carried out experiments in which unstimulated PBL, control and irradiated with $0.5 \mathrm{~Gy}$ or $3 \mathrm{~Gy}$ of X-rays, were subjected to treatment with calyculin A ( $50 \mathrm{nM})$ in the presence of ATP and the CDK1-cyclin B complex (at the concentration of 0,5 , or 20 units per lymphocyte culture). The experimental conditions were as described in the papers of Prasanna et al. [9, 10] with the exception of using calyculin A instead of okadaic acid. The reason for this modification was that in the pilot experiments, calyculin A proved to be a stronger phosphatase inhibitor and its effect was faster. However, under these experimental conditions, we did not achieve the optimal chromosomal condensation that would allow visualization of the chromosomal territories. This resulted possibly from the toxicity of calyculin A. It caused considerable cell death after 1 hour, whereas in the surviving cells, the CDK1-cyclin B complex acted more slowly. In both experiments, independent of the CDK1-cyclin B complex concentration, the chromatin was insufficiently condensed and the number of cells was too low to carry out the analysis.

Therefore, in the subsequent experiments carried out as above, $0.75 \mu \mathrm{M}$ okadaic acid was used, as originally applied by Prasanna et al. [9, 10]. Using the okadaic acid, we obtained cell preparations with both uncondensed and condensed chromatin (Fig. 5); however, the number of cells that were suitable for analysis using the FISH technique seemed to be too low. The successful painting of chromosomal territories in the stimulated lymphocytes allowed us to conclude that when there was an unsatisfactory signal on the preparations of the unstimulated

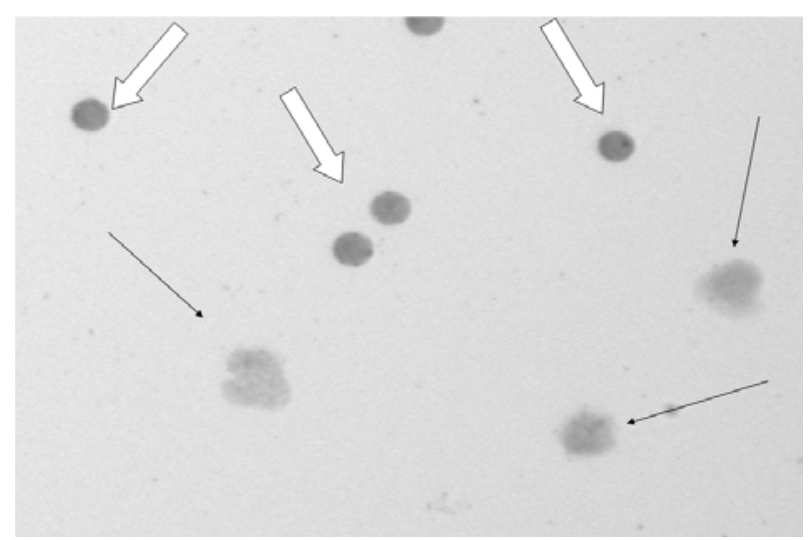

Fig. 5. Chromatin in unstimulated human lymphocytes partly condensed by treatment with $0.75 \mu \mathrm{M}$ okadaic acid in the presence of ATP and cyclin-dependent kinase 1-cyclin B (20 units per culture). Empty arrows indicate uncondensed nuclei, full arrows - those with partly condensed chromatin. lymphocytes treated with phosphatase inhibitors, the cause was not the applied reagents. In addition, personal communication from the co-author of the RICA method, Dr William F. Blakely (Armed Forces Radiobiology Research Institute, USA), disclosed several pitfalls that must be avoided.

\section{Pitfalls to avoid}

The CDK1 cyclin B complex cannot be kept frozen for more than three months. Not every preparation is adequate and must be tested for its potential to stimulate chromatin condensation. After testing, we recommend the use of the product applied in the original method, that of the New England Biolabs, Beverly, MA, USA. The complex (about $60 \mathrm{kDa}$ ) is taken up by mammalian cells by phagocytosis, pinocytosis, or endocytosis; there are no receptors that could facilitate the uptake. This might have been the reason for the above-described difficulties with obtaining the adequately condensed chromatin.

To see the supernumerary chromosome territories after chromosome painting in the irradiated cells, the nuclei should be well flattened, thus showing a larger surface. This can be achieved by using the Cytospin for microscopic preparations. Nevertheless, in our experience, the differences between hand application and Cytospin were insignificant, with the exception of 0 and 0.5 Gy (Figs. 6 and 7).

The dose-effect curves obtained for Cytospin and the hand application of lymphocytes exposed to $\mathrm{X}$ or $\mathrm{Co}^{60} \gamma$ rays are shown in Fig. 5. The following parameters were fitted for the $0-3$ Gy range:

$$
\begin{gathered}
\mathrm{Y}=0.0461( \pm 0.0070)+0.0253( \pm 0.0078) * \mathrm{D} ; \\
\mathrm{X} \text {-rays, hand application; }
\end{gathered}
$$

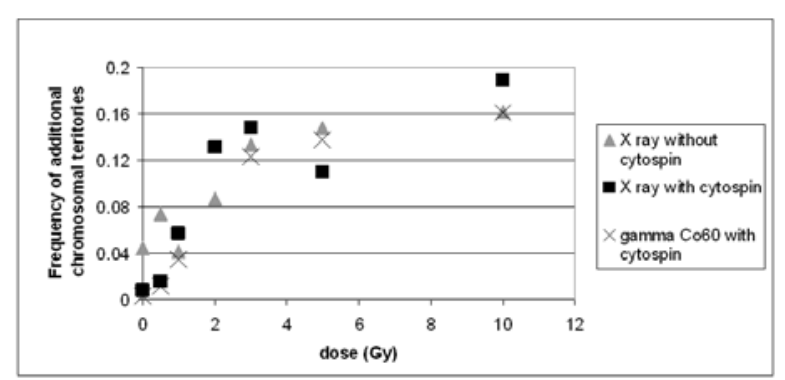

Fig. 6. The dependence of the number of additional chromosomal territories on X- or $\gamma$-ray dose. Differences are shown between application by Cytospin or manually.

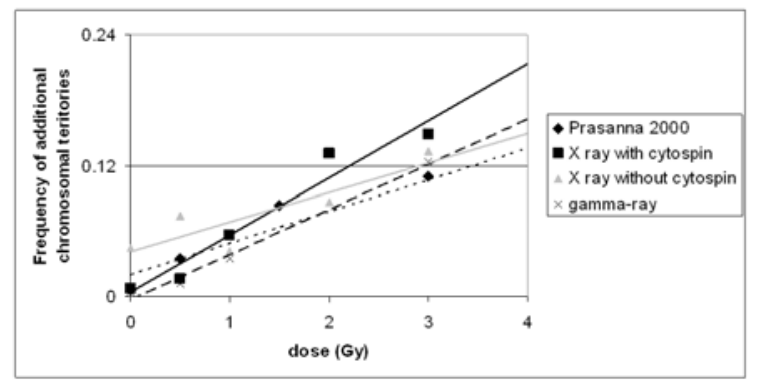

Fig. 7. Calibration curves obtained as described in the present paper and that published by Prasanna et al. [9]. 


$$
\begin{gathered}
\mathrm{Y}=0.0061( \pm 0.0041)+0.0504( \pm 0.0065) * \mathrm{D} ; \\
\mathrm{X} \text {-rays, Cytospin application, } \\
\mathrm{Y}=0.0029( \pm 0.0023)+0.0365( \pm 0.0052) * \mathrm{D} ; \\
\mathrm{Co}^{60} \gamma \text { rays, Cytospin application. }
\end{gathered}
$$

Figure 5 shows that the dose-effect curves obtained in our laboratory are close to that published by Prasanna et al. [9]. That for X-ray irradiated cells applied by Cytospin has the $\alpha$ parameter higher than for $\gamma$-irradiated cells, whereas the $\alpha$ value is lower for hand-applied X-irradiated cells.

\section{Comparison with other biodosimetry methods}

The RICA method was compared with the other PCC methods described as applicable for a range of higher radiation doses: PCC induced by fusion with $\mathrm{CHO}$ cells and chemically induced PCC. The PCC induced by fusion of lymphocytes with mitotic $\mathrm{CHO}$ cells is carried out in a polyethylene glycol milieu $[22,23]$. Due to the difference in the morphology of the condensed human and Chinese hamster chromosomes, it is possible to exclusively score the supernumerary fragments of the chromosomes of human origin. There should be 46 PCC fragments in the undamaged lymphocyte, whereas the additional fragments resulting from DNA damage are in direct proportion to the radiation dose (Fig. 6). The method is used in the dose range 0-20 (30) Gy. The results can be obtained very quickly, that is, during one day. However, due to the DNA repair taking place, the number of PCC fragments decreases. Therefore, to apply this method for biodosimetry, at least four calibration curves should be prepared for $1,8,24$, and $48 \mathrm{~h}$ after exposure [24]. The calibration curve was obtained in our laboratory for only 1 hour after exposure and in the dose range of 0-6 Gy of $\mathrm{Co}^{60} \gamma$ rays (fitted for linear dependence):

$$
\mathrm{Y}=0.0000\left(\underset{\mathrm{Co}^{60} \gamma \text { rays }}{( \pm 0.0000)+3.4540( \pm 0.1863) * \mathrm{D} ;}\right.
$$

Although the CHO cell fusion-induced PCC method is technically exacting, the calibration curve obtained in our laboratory is similar to those obtained in the Athens and Leiden laboratories and based on the data for 1 hour post-exposure and the dose range $0-10$ Gy X-rays, where the $\alpha$ parameter equals $4.1(\mathrm{Y}=0.0+4.1 * \mathrm{D}[25])$.

The chemically induced PCC test has been used in biodosimetry for 20 years and is considered as advantageous when compared with the dicentric test because it can be applied for the estimation of doses as high as several tens of Gy. We used calyculin A added to lymphocyte cultures $48 \mathrm{~h}$ after treatment with phytohemagglutinin. The same microscopic slides can be used for analysis of additional PCC fragments, long chromosome and ring frequency (Fig. 2).

The following parameters were established for the dose-effect curves for X-ray irradiation (fitted for linear dependence):

- ring frequency: $\mathrm{Y}=-0.0286( \pm 0.0016)+0.0309$
* D $( \pm 0.0014)$, goodness of fit $=0.6730$, dose interval 1-20 Gy;

- frequency of long chromosomes: $\mathrm{Y}=-0.0235$ $( \pm 0.0027)+0.0235 * \mathrm{D}( \pm 0.0027)$, goodness of fit $=0.5001$, dose interval $1-20 \mathrm{~Gy}$;

- frequency of PCC fragments: $\mathrm{Y}=-0.1743$ $( \pm 0.0312)+0.3552 * \mathrm{D}( \pm 0.0269)$, dose interval $0-20 \mathrm{~Gy}$.

The advantages and disadvantages of different PCC methods are compared in a tabular format (Table 1).

\section{Conclusions}

The data presented here allow the following conclusions concerning RICA application in biodosimetry: - Okadaic acid is better suited in RICA than calyculin for phosphatase inhibition.

- Although with the use of the published RICA protocol, the reported chromatin condensation level is hard to achieve, the condensation obtained by us is sufficient to carry out the analysis.

- The unsatisfactory chromosome condensation may be caused by the quality of the CDK1-cyclin B complex and its scanty uptake by the cells; the uptake mechanism is not sufficiently understood.

- In our hands, a linear dose-effect relation for X- or $\gamma$-rays was obtained with the RICA method only for the 0-3 Gy dose range. At higher doses no linear increase was noted, in contrast with other data [9] showing a linear increase up to 7.5 Gy.

- The quality of the microscopic preparations for the scoring of additional chromosome territories is better when Cytospin is used instead of a manual application.

- The method should be validated. Since its use is not time-consuming and easy for automation, it is ideally suited for triage tests.

Acknowledgments. The assistance of Monica Borrin-Flint in the preparation of the manuscript is gratefully acknowledged. The work was supported by Strategic Programme of the National Centre for Research and Development "Safe nuclear power engineering development technologies", Research task no. 6 "Development of nuclear safety and radiological protection methods for the nuclear power engineering's current and future needs", Objective 2. "Development of the biodosimetry and biophysics markers of ionizing radiation in leaving beings". Contract: SP/J/6/143 339/M.

\section{List of abbreviations}

$\begin{array}{ll}\text { ATP } & \text { - adenosine triphosphate } \\ \text { CDK1 } & \text { - cykline-dependent kinase } 1 \\ \text { CHO } & \text { - Chinese hamster ovary cells } \\ \text { DAPI } & -4 \text { ',6-diamidino-2-phenylindole } \\ \text { FBS } & \text { - fetal bovine serum } \\ \text { FISH } & \text { - fluorescence in situ hybridization } \\ \text { PBL } & \text { - peripheral blood lymphocytes } \\ \text { PBS } & \text { - phosphate buffered saline }\end{array}$




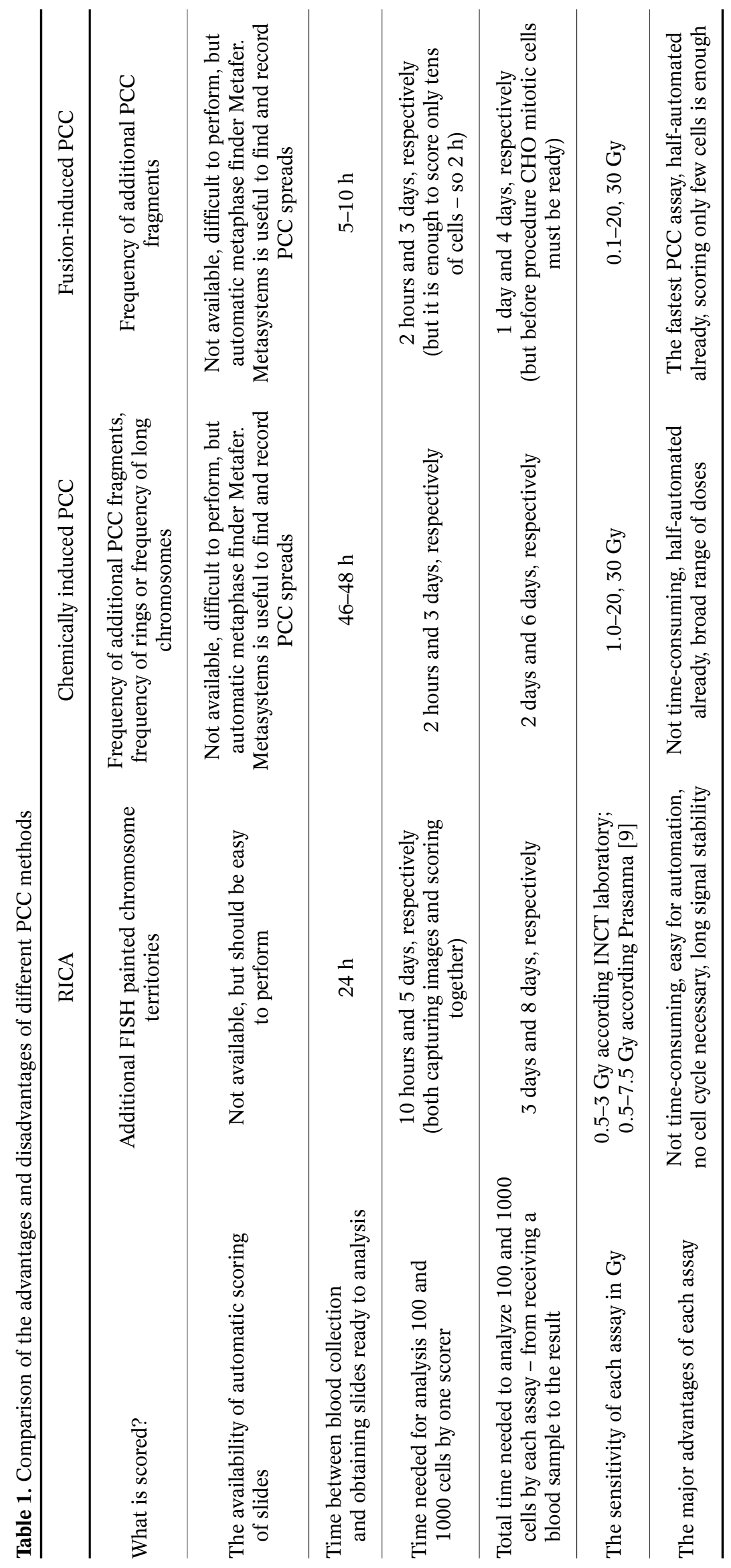


PCC - premature chromosome condensation

PEG - polyethylene glycol

PP1, PP2A - serine/threonine protein phosphatases

RICA - rapid interphase chromosome assay

RPM - revolutions per minute

SSC - saline-sodium citrate buffer

\section{References}

1. Flegal, F. N., Devantier, Y., McNamee, J. P., \& Wilkins, R. C. (2010). Quickscan dicentric chromosome analysis for radiation biodosimetry. Health Phys., 98, 276-281. DOI: 10.1097/HP.0b013e3181aba9c7.

2. Flegal, F. N., Devantier, Y., Marro, L., \& Wilkins, R. C. (2012). Validation of QuickScan dicentric chromosome analysis for high throughput radiation biological dosimetry. Health Phys., 102, 143-153. DOI: 10.1097/HP.0b013e3182307758.

3. Romm, H., Ainsbury, E., Barnard, S., Barrios, L., Barquinero, J. F., Beinke, C., Deperas, M., Gregoire, E., Koivistoinen, A., Lindholm, C., Moquet, J., Oestreicher, U., Puig, R., Rothkamm, K., Sommer, S., Thierens, H., Vandersickel, V., Vral, A., \& Wojcik, A. (2014). Validation of semi-automatic scoring of dicentric chromosomes after simulation of three different irradiation scenarios. Health Phys., 106(6), 764-771. DOI: 10.1097/HP.0000000000000077.

4. Thierens, H., Vral, A., Vandevoorde, C., Vandersickel, V., de Gelder, V., Romm, H., Oestreicher, U., Rothkamm, K., Barnard, S., Ainsbury, E., Sommer, S., Beinke, C., \& Wojcik, A. (2014). Is a semi-automated approach indicated in the application of the automated micronucleus assay for triage purposes? Radiat. Prot. Dosim., 159(1/4), 87-94. DOI: 10.1093/rpd/ ncu130. Epub 2014 Apr 17.

5. McNamee, J. P., Flegal, F. N., Greene, H. B., Marro, L., \& Wilkins, R. C. (2009). Validation of the cytokinesis-block micronucleus (CBMN) assay for use as a triage biological dosimetry tool. Radiat. Prot. Dosim., 135(4), 232-242. DOI: 10.1093/rpd/ncp119.

6. Roch-Lefèvre, S., Mandina, T., Voisin, P., Gaëtan, G., Mesa, J. E., Valente, M., Bonnesoeur, P., García, O., Voisin, P., \& Roy, L. (2010). Quantification of gamma-H2AX foci in human lymphocytes: a method for biological dosimetry after ionizing radiation exposure. $R a$ diat. Res., 174(2), 185-194. DOI: 10.1667/RR1775.1.

7. Barnard, S., Ainsbury, E. A., Al-Hafidh, J., Hadjidekova, V., Hristova, R., Lindholm, C., Monteiro Gil, O., Moquet, J., Moreno, M., Rößler, U., Thierens, H., Vandevoorde, C., Vral, A., Wojewódzka, M., \& Rothkamm, K. (2014). The first gamma-H2AX biodosimetry intercomparison exercise of the developing European biodosimetry network RENEB. Radiat. Prot. Dosim., pii: ncu259. [Epub ahead of print] PubMed PMID: 25118318.

8. Rothkamm, K., Barnard, S., Ainsbury, E. A., AlHafidh, J., Barquinero, J. F., Lindholm, C., Moquet, J., Perälä, M., Roch-Lefèvre, S., Scherthan, H., Thierens, H., Vral, A., \& Vandersickel, V. (2013). Manual versus automated $\gamma-\mathrm{H} 2 \mathrm{AX}$ foci analysis across five European laboratories: can this assay be used for rapid biodosimetry in a large scale radiation accident? Mutat. Res., 756(1/2), 170-173. DOI: 10.1016/j. mrgentox.2013.04.012.

9. Prasanna, P. G., Escalada, N. D., \& Blakely, W. F. (2000). Induction of premature chromosome condensation by a phosphatase inhibitor and a protein kinase in unstimulated human PBL: a simple and rapid technique to study chromosome aberrations using specific whole-chromosome DNA hybridization probes for biological dosimetry. Mutat. Res., 466(2), 131-141. PubMed PMID: 10727901.

10. Prasanna, P. G., Hamel, C. J., Escalada, N. D., Duffy, K. L., \& Blakely, W. F. (2002). Biological dosimetry using human interphase peripheral blood lymphocytes. Mil. Med., 167(Suppl. 2), 10-12. PubMed PMID: 11873484.

11. Coco-Martin, J. M., \& Begg, A. C. (1997). Detection of radiation-induced chromosome aberrations using fluorescence in situ hybridization in drug-induced premature chromosome condensations of tumor cell lines with different radiosensitivities. Int. J. Radiat. Biol., 71(3), 265-273. PMID: 9134016.

12. Durante, M., George, K., \& Yang, T. C. (1996). Biological dosimetry by interphase chromosome painting. Radiat. Res., 145(1), 53-60. PMID: 8532837.

13. Gotoh, E., \& Durante, M. (2006). Chromosome condensation outside of mitosis: Mechanisms and new tools. J. Cell Physiol., 209(2), 297-304. PMID: 16810672.

14. Gotoh, E., \& Tanno, Y. (2005). Simple biodosimetry method for cases of high-dose radiation exposure using the ratio of the longest/shortest length of Giemsa stained drug-induced prematurely condensed chromosomes (PCC). Int. J. Radiat. Biol., 81(5), 379-385. PMID: 16076753

15. Gotoh, E., Tanno, Y., \& Takakura, K. (2005). Simple biodosimetry method for use in cases of high-dose radiation exposure that scores the chromosome number of Giemsa-stained drug-induced prematurely condensed chromosomes (PCC). Int. J. Radiat. Biol., 81(1), 33-40. PMID: 15962761.

16. Lamadrid, A. I., García, O., Delbos, M., Voisin, P., \& Roy, L. (2007). PCC-ring induction in human lymphocytes exposed to gamma and neutron irradiation. $J$. Radiat. Res., 48(1), 1-6. PMID: 17102580.

17. Prasanna, P. G. S., Muderhwa, J. M., Miller, A. C., Grace, M. B., Salter, C. A., \& Blakely, W. F. (2004). Diagnostic biodosimetry response for radiation disasters: Current research and service activities at Armed Forces Radiobiology Research Institute, USA. Armed Forces Radiobiology Research Institute, USA. (RTO-MP-HFM-108).

18. Wang, Z. Z., Li, W. J., Zhi, D. J., Jing, X. G., Wei, W., Gao, Q. X., \& Liu, B. (2007). Biodosimetry estimate for high-LET irradiation. Radiat. Environ. Biophys., 46(3), 229-235. PMID: 17443338.

19. Wang, Z. Z., Li, W. J., Zhi, D. J., Gao, Q. X., Qu, Y., \& Wang, B. Q. (2009). Prematurely condensed chromosome fragments in human lymphocytes induced by high doses of high-linear-energy-transfer irradiation. Mutat. Res., 679(1/2), 9-12. DOI: 10.1016/j. mrgentox.2009.08.001. Epub 2009 Aug 8.

20. Durante, M., Furusawa, Y., \& Gotoh, E. (1998). A simple method for simultaneous interphase-metaphase chromosome analysis in biodosimetry. Int. J. Radiat. Biol., 74(4), 457-462. PMID: 9798956.

21. Resjö, S., Oknianska, A., Zolnierowicz, S., Manganiello, V., \& Degerman, E. (1999). Phosphorylation and activation of phosphodiesterase type 3B (PDE3B) in adipocytes in response to serine/threonine phosphatase inhibitors: deactivation of PDE3B in vitro by protein phosphatase type 2A. Biochem. J., 341(3), 839-845. PMC 1220425.

22. Pantelias, G. E., \& Maillie, H. D. (1983). A simple method for premature chromosome condensation induction in primary human and rodent cells us- 
ing polyethylene glycol. Somatic Cell Genet., 9(5), 533-547. PMID: 6623312.

23. Pantelias, G. E., \& Maillie, H. D. (1984). The use of peripheral blood mononuclear cell prematurely condensed chromosomes for biological dosimetry. Radiat. Res., 99(1), 140-150. PMID: 6539927.

24. Lamadrid Boada, A. I., Romero Aguilera, I., Terzoudi, G. I., González Mesa, J. E., Pantelias, G., \& García, O. (2013). Rapid assessment of high-dose radiation exposures through scoring of cell-fusion-induced premature chromosome condensation and ring chromosomes. Mutat. Res., 757(1), 45-51. DOI: 10.1016/j. mrgentox.2013.06.021. Epub 2013 July 12.

25. Darroudi, F., Terzoudi, G. I., Pantelias, G., Sommer, S., \& Hajidekova, V. (2013). RENEB (Realizing the European Network of Biodosimetry). Periodic Report 1 January 2012 - 30 June 2013, WP 1, Task 4 for EC. 